\title{
Levels of Cornell Voltage and Cornell Product for Predicting Cardiovascular and Stroke Mortality and Morbidity in the General Japanese Population
}

\author{
Joji Ishikawa, MD, PhD; Shizukiyo Ishikawa, MD, PhD; Kazuomi Kario, MD, PhD; \\ Jichi Medical School (JMS) Cohort Study Investigators Group
}

\begin{abstract}
Background: ECG-diagnosed left ventricular hypertrophy (LVH), the Cornell voltage (CV: $\geq 2.8 \mathrm{mV}$ in males and $\geq 2.0 \mathrm{mV}$ in females) or Cornell product (CP: $\geq 244.0 \mathrm{mV} \times \mathrm{ms}$ ), were selected in Western countries for their ability to diagnose anatomical $\mathrm{LVH}$.

Methods and Results: We aimed to elucidate the CV and CP values that were associated with a significantly increased risk of cardiovascular or stroke mortality and morbidity in a Japanese general population ( $n=10,172)$. In the receiver-operating curves analysis of $\mathrm{CV}$ and $\mathrm{CP}$ for predicting the risks, the area under the curve in females was greater than in males. In a quintile-based multivariate analysis that was performed separately for females and males, the mortality and morbidity risks of $\mathrm{CV}$ were significantly increased at the highest quintile of $\mathrm{CV}(>1.71 \mathrm{mV})$ in females. In males, the mortality risk was significantly increased at the highest quintile of CV (>2.04 mV). Additionally, in the parallel analysis of $\mathrm{CP}$ that included both males and females, the morbidity risk was significantly elevated in subjects with $\mathrm{CP}$ belonging to the 4 th $(158.7-193.4 \mathrm{mV} \times \mathrm{ms}$; hazard ratio=1.387) or 5th quintiles $(\geq 193.5 \mathrm{mV} \times \mathrm{ms}$; hazard ratio $=1.507)$, compared with those with $\mathrm{CP}$ values within the lowest quintile $(<101.9 \mathrm{mV} \times \mathrm{ms})$.
\end{abstract}

Conclusions: Cardiovascular and stroke risks may be elevated at lower levels of $\mathrm{CV}$ and $\mathrm{CP}$ in Japanese subjects, especially females. (Circ J 2014; 78: 465-475)

Key Words: Cornell product; Cornell voltage; ECG; Left ventricular hypertrophy; Sokolow-Lyon voltage

$\mathbf{L}$ eft ventricular hypertrophy (LVH) can be evaluated using 12-lead $\mathrm{ECG}^{1}$ and for the diagnosis of ECG$\mathrm{LVH}$, either the standard voltage criteria reported by Sokolow-Lyon ${ }^{2}$ or the Cornell voltage (CV) and Cornell product $(\mathrm{CP})(\mathrm{CV} \times \mathrm{QRS}$ duration $)$ criteria has been used in clinical studies. ${ }^{3}$ The cutoff levels for ECG-LVH (CV $\geq 2.8 \mathrm{mV}$ in males, $\geq 2.0 \mathrm{mV}$ in females; $\mathrm{CP} \geq 244.0 \mathrm{mV} \times \mathrm{ms}$, Sokolow-Lyon voltage $\geq 3.8 \mathrm{mV})^{4}$ were chosen for their ability to diagnose echocardiographic $\mathrm{LVH}^{5-7}$ in Western populations. In addition, these 3 criteria for ECG-LVH were reported as associated with increased morbidity and mortality; ${ }^{8-11}$ however, they displayed low sensitivity for diagnosing echocardiographic $\mathrm{LVH}^{, 12}$ and the risks of mortality ${ }^{13}$ and stroke events ${ }^{14}$ associated with ECG-LVH were found to be independent of echocardiographic LVH. Recently, ECG-LVH has been considered to be a marker of electrical remodeling of the myocardium, rather than just a marker of anatomical LVH. ${ }^{15}$ Therefore, the threshold levels of the abovementioned parameters for diagnosing echocardiographic LVH might differ from the levels at which the risk of cardiovascular or stroke morbidity is significantly increased.

The purpose of this study was to evaluate the $\mathrm{CV}, \mathrm{CP}$, and Sokolow-Lyon voltage at which individuals from a Japanese general population are at a significantly increased risk of cardiovascular and stroke mortality/morbidity.

Methods
Subjects
The Jichi Medical School (JMS) Cohort Study was initiated
in 1992, with the primary aim of clarifying the risk factors
for cardiovascular and cerebrovascular disease in the general
Japanese population. The details of the protocol of the JMS
Cohort Study have been reported previously. ${ }^{\mathbf{1 6}, 17}$ Baseline data
were collected between April 1992 and July 1995 in 12 rural
districts of Japan (Iwaizumi, Tako, Kuze, Sakuma, Sakugi,
Okawa, Ainoshima, Akaike, Wara, Hokudan, Yamato, and
Takasu) using a government-sponsored mass screening sys-

Received April 9, 2013; revised manuscript received September 6, 2013; accepted October 2, 2013; released online November 26,2013 Time for primary review: 20 days

Division of Cardiovascular Medicine, Department of Internal Medicine, Jichi Medical University School of Medicine (J.I., K.K.); Division of Community and Family Medicine, Center for Community Medicine, Jichi Medical University (S.I.), Shimotsuke, Japan

Mailing address: Joji Ishikawa, MD, PhD, Division of Cardiovascular Medicine, Department of Medicine, Jichi Medical University, School of Medicine, 3311-1 Yakushiji, Shimotsuke 329-0498, Japan. E-mail: george@jichi.ac.jp

ISSN-1346-9843 doi:10.1253/circj.CJ-13-0470

All rights are reserved to the Japanese Circulation Society. For permissions, please e-mail: cj@j-circ.or.jp 


\begin{tabular}{|c|c|c|c|c|}
\hline Variable & $\begin{array}{c}\text { Total } \\
(n=10,172)\end{array}$ & $\begin{array}{c}\text { Males } \\
(n=3,830)\end{array}$ & $\begin{array}{l}\text { Females } \\
(n=6,342)\end{array}$ & $\begin{array}{l}\mathrm{P} \text { between males } \\
\text { and females }\end{array}$ \\
\hline Age, years & $55.4 \pm 11.2$ & $55.2 \pm 11.7$ & $55.5 \pm 11.0$ & 0.112 \\
\hline Body mass index, $\mathrm{kg} / \mathrm{m}^{2}$ & $23.1 \pm 3.1$ & $23.0 \pm 2.9$ & $23.2 \pm 3.2$ & $<0.001$ \\
\hline Smoking habit & & & & $<0.001$ \\
\hline Past smoker, \% & 12.6 & 28.3 & 2.9 & \\
\hline Current smoker, \% & 22.6 & 50.1 & 5.7 & \\
\hline Alcohol drinking $>20 \mathrm{~g} /$ day & 27.6 & 27.0 & 28.0 & 0.257 \\
\hline Hyperlipidemia, \% & 35.4 & 34.9 & 35.8 & 0.363 \\
\hline Status of diabetes & & & & $<0.001$ \\
\hline Impaired fasting glucose, $\%$ & 2.6 & 3.6 & 1.9 & \\
\hline Diabetes, \% & 3.5 & 5.0 & 2.6 & \\
\hline Systolic blood pressure, $\mathrm{mmHg}$ & $129.3 \pm 21.0$ & $131.4 \pm 20.6$ & $128.1 \pm 21.2$ & $<0.001$ \\
\hline Diastolic blood pressure, $\mathrm{mmHg}$ & $77.4 \pm 12.3$ & $79.3 \pm 12.3$ & $76.3 \pm 12.2$ & $<0.001$ \\
\hline Hypertension, \% & 34.2 & 36.9 & 32.6 & $<0.001$ \\
\hline Antihypertensive medication use, $\%$ & 11.1 & 9.4 & 12.2 & $<0.001$ \\
\hline $\mathrm{S}$ in lead $\mathrm{V} 1, \mathrm{mV}$ & $0.93 \pm 0.41$ & $0.98 \pm 0.44$ & $0.91 \pm 0.39$ & $<0.001$ \\
\hline$R$ in lead V5, $\mathrm{mV}$ & $1.74 \pm 0.62$ & $1.96 \pm 0.67$ & $1.60 \pm 0.55$ & $<0.001$ \\
\hline SV1+RV5, mV & $2.67 \pm 0.83$ & $2.94 \pm 0.87$ & $2.51 \pm 0.76$ & $<0.001$ \\
\hline $\mathrm{S}$ in lead $\mathrm{V} 3, \mathrm{mV}$ & $1.03 \pm 0.53$ & $1.22 \pm 0.57$ & $0.93 \pm 0.48$ & $<0.001$ \\
\hline $\mathrm{R}$ in lead aVL, $\mathrm{mV}$ & $0.35 \pm 0.24$ & $0.33 \pm 0.25$ & $0.36 \pm 0.24$ & $<0.001$ \\
\hline SV3+RaVL, mV & $1.38 \pm 0.58$ & $1.54 \pm 0.62$ & $1.28 \pm 0.54$ & $<0.001$ \\
\hline QRS duration, ms & $85.4 \pm 13.8$ & $89.1 \pm 14.1$ & $83.2 \pm 13.0$ & $<0.001$ \\
\hline Cornell product, $\mathrm{mV} \times \mathrm{ms}$ & $150.1 \pm 57.7$ & $138.3 \pm 62.2$ & $157.2 \pm 53.6$ & $<0.001$ \\
\hline
\end{tabular}

Data are shown as mean \pm standard deviation (SD) or percentage. $P$ values were evaluated using Student's t-test between men and women. $\mathrm{P}<0.05$ was considered statistically significant.

tem (Data S1). In each community, a local government office sent personal invitations by mail to all potential subjects in accordance with the Health and Medical Service Law for the aged. At baseline, the total number of subjects in the JMS Cohort Study was 12,490 (4,911 males and 7,579 females). The participation rate varied from community to community (26-90\%), and the overall participation rate of those invited to the mass screening examination program was $65.4 \% .{ }^{18}$

\section{ECG Measurement and Interpretation}

ECG were obtained at a paper speed of $25 \mathrm{~mm} / \mathrm{s}$ and a gain of $10 \mathrm{~mm} / \mathrm{mV}$ (or $5 \mathrm{~mm} / \mathrm{mV}$ ) using the ECG devices at the participating institutes. A trained person, who did not know the subjects' backgrounds, assessed the subjects' ECG parameters at a central laboratory using a ruler with $0.01-\mathrm{mm}$ gradations. Both the Sokolow-Lyon voltage (SV1+RV5) and CV $(\mathrm{RaVL}+\mathrm{SV} 3)^{3,19}$ were measured. QRS duration was measured manually from lead II (or lead I or III if the measurement of QRS duration was difficult from lead II) based on a single heartbeat. $\mathrm{CP}$ without adjustment for sex was calculated as the product of $\mathrm{CV}$ and the subsequent QRS duration. CP with adjustment for sex was also calculated using the aforementioned equation after $0.6 \mathrm{mV}$ was added to females' CV, following previous reports ${ }^{3,19}$ and the Japanese Society of Hypertension 2009 (JSH2009) guideline for the Management of Hypertension. ${ }^{4}$ The interobserver (between the trained person and a cardiologist) and intraobserver (of the trained person) variations in $\mathrm{CV}$ were $0.09 \pm 0.08 \mathrm{mV}$ and $0.02 \pm 0.05 \mathrm{mV}$, respectively, and those of the CP were $1.5 \pm 35.7 \mathrm{mV} \times \mathrm{ms}$ and $21.6 \pm 27.0 \mathrm{mV} \times \mathrm{ms}$, respectively. We compared the SokolowLyon voltage, $\mathrm{CV}$ and $\mathrm{CP}$ data obtained in the present study with those described in a previous report about the Losartan Intervention for Endpoint (LIFE) reduction in hypertension study $^{20}$ and those written in the JSH 2009 guideline $^{4}$ [in which Sokolow-Lyon LVH is defined as $\geq 3.8 \mathrm{mV}$ (38 mm); CV $\mathrm{LVH}$ is defined as $2.8 \mathrm{mV}(28 \mathrm{~mm})$ in males and $2.0 \mathrm{mV}$ $(20 \mathrm{~mm})$ in females; and CP LVH is defined as $244.0 \mathrm{mV} \times \mathrm{ms}$ $(2,440 \mathrm{~mm} \times \mathrm{ms})]$.

\section{Informed Consent}

The internal review board of Jichi Medical University School of Medicine approved the study and written informed consent for the study was given individually by all subjects during the mass screening health check-up examinations.

\section{Follow-up and Diagnostic Criteria}

The mass screening examination system was used to check the subjects every year for 10 years. After the initial follow-up period of 10 years, follow-up was extended until the end of 2005 for mortality only. We asked the subjects directly whether they had suffered a stroke or cardiovascular event since enrolling in the study. When a subject did not undergo the annual screening examination, we contacted them or their family members by mail or phone to confirm whether they had suffered any cardiovascular events or died. If a subject had been taken to a medical facility because of a cardiovascular event or death, a doctor or health nurse associated with the JMS Cohort Study visited the facility and checked the patient's medical records. When an incident case was suspected, we applied for permission and then photocopied any relevant brain computed tomography or magnetic resonance imaging (if a cerebrovascular event was suspected) scans and/or ECG (if myocardial infarction was suspected). When a subject that we were unable to contact during the follow-up period died, a death certificate was collected from the appropriate public health center with the permission of the Agency of General Affairs and the Ministry 


\begin{tabular}{|c|c|c|c|c|c|c|c|c|c|c|c|c|}
\hline \multirow{2}{*}{ Males } & \multicolumn{4}{|c|}{ All-cause mortality } & \multicolumn{4}{|c|}{ CCS mortality } & \multicolumn{4}{|c|}{$\begin{array}{c}\text { CCS morbidity } \\
\text { (fatal and nonfatal) }\end{array}$} \\
\hline & HR & \multicolumn{2}{|c|}{$95 \% \mathrm{Cl}$} & $P$ value & HR & \multicolumn{2}{|c|}{$95 \% \mathrm{Cl}$} & $P$ value & HR & \multicolumn{2}{|c|}{$95 \% \mathrm{Cl}$} & $P$ value \\
\hline \multirow{2}{*}{\multicolumn{13}{|c|}{ Cornell voltage per $0.1 \mathrm{mV}$ increase }} \\
\hline & & & & & & & & & & & & \\
\hline Unadjusted & 1.028 & 1.014 & 1.041 & $<0.001$ & 1.045 & 1.020 & 1.070 & $<0.001$ & 1.038 & 1.020 & 1.056 & $<0.001$ \\
\hline Age adjusted & 1.025 & 1.011 & 1.040 & 0.001 & 1.048 & 1.019 & 1.077 & $<0.001$ & 1.038 & 1.018 & 1.058 & $<0.001$ \\
\hline Multivariate adjusted & 1.025 & 1.010 & 1.041 & 0.001 & 1.040 & 1.008 & 1.072 & 0.013 & 1.022 & 1.001 & 1.044 & 0.043 \\
\hline \multicolumn{13}{|c|}{ Sokolow-Lyon voltage per $0.1 \mathrm{mV}$ increase } \\
\hline Unadjusted & 1.002 & 0.991 & 1.012 & 0.778 & 1.022 & 1.000 & 1.046 & 0.052 & 1.032 & 1.017 & 1.047 & $<0.001$ \\
\hline Age adjusted & 1.000 & 0.990 & 1.011 & 0.950 & 1.020 & 0.998 & 1.042 & 0.069 & 1.029 & 1.015 & 1.044 & $<0.001$ \\
\hline Multivariate adjusted & 0.998 & 0.987 & 1.008 & 0.653 & 1.013 & 0.991 & 1.035 & 0.247 & 1.019 & 1.005 & 1.034 & 0.009 \\
\hline \multicolumn{13}{|l|}{ Females } \\
\hline \multicolumn{13}{|c|}{ Cornell voltage per $0.1 \mathrm{mV}$ increase } \\
\hline Unadjusted & 1.058 & 1.042 & 1.073 & $<0.001$ & 1.078 & 1.055 & 1.101 & $<0.001$ & 1.080 & 1.065 & 1.095 & $<0.001$ \\
\hline Age adjusted & 1.031 & 1.011 & 1.052 & 0.002 & 1.063 & 1.028 & 1.101 & $<0.001$ & 1.072 & 1.051 & 1.093 & $<0.001$ \\
\hline Multivariate adjusted & 1.031 & 1.010 & 1.052 & 0.003 & 1.058 & 1.021 & 1.097 & 0.002 & 1.056 & 1.033 & 1.079 & $<0.001$ \\
\hline \multicolumn{13}{|c|}{ Sokolow-Lyon voltage per $0.1 \mathrm{mV}$ increase } \\
\hline Unadjusted & 1.045 & 1.031 & 1.058 & $<0.001$ & 1.047 & 1.021 & 1.073 & $<0.001$ & 1.052 & 1.035 & 1.069 & $<0.001$ \\
\hline Age adjusted & 1.029 & 1.016 & 1.043 & $<0.001$ & 1.028 & 1.004 & 1.054 & 0.025 & 1.038 & 1.021 & 1.054 & $<0.001$ \\
\hline Multivariate adjusted & 1.029 & 1.015 & 1.043 & $<0.001$ & 1.029 & 1.003 & 1.056 & 0.029 & 1.028 & 1.011 & 1.045 & 0.001 \\
\hline
\end{tabular}

In the multivariate-adjusted model, age, body mass index, alcohol drinking habit, smoking status, presence of hyperlipidemia, status of diabetes, systolic blood pressure, and antihypertensive medication use were also entered into the Cox regression analysis.

$\mathrm{CCS}$, combined cardiovascular and stroke; HR, hazard ratio; Cl, confidence interval.

of Health, Labor, and Welfare. Data on changes of residence during the study were obtained annually from each municipal government. Cause of death and events were determined independently by an endpoints committee, which included radiologists, neurologists, and cardiologists, in accordance with the criteria outlined by the World Health Organization's Monitoring of Trends and Determinants in Cardiovascular Disease (WHO MONICA) project. ${ }^{21}$ The diagnostic criteria are shown in Data S1.

\section{Statistical Analysis}

Among the 12,490 subjects who were initially enrolled in the JMS Cohort Study, we analyzed 10,172 subjects who had adequate follow-up data, after excluding 2,318 subjects with no ECG recordings ( $n=1,285)$, immeasurable ECG findings $(n=28)$, complete left bundle branch block $(\mathrm{n}=20)$, complete right bundle branch block $(\mathrm{n}=189)$, QRS duration $>200 \mathrm{~ms}(\mathrm{n}=3)$, atrial fibrillation $(n=53)$, no blood pressure data $(n=160)$, no information about their antihypertensive medication use $(n=430)$, or a history of myocardial infarction and/or stroke $(n=150)$.

Data are shown as the mean \pm 1 standard deviation for continuous variables, and as percentages for dichotomous variables. Differences in characteristics between the male and female subjects were evaluated using Student's t-test or the chi-square test. The area under the receiver-operating characteristic (AUC) curve was used to compare the abilities of the Cornell and Sokolow-Lyon voltages to predict combined cardiovascular and stroke (CCS) mortality and morbidity. KaplanMeier curves were constructed to visualize the risk levels associated with each CP quintile in the unadjusted models. The mortality and morbidity risk levels in both the unadjusted models and those that had been adjusted for conventional cardiovascular risk factors were evaluated using Cox regression analysis in all subjects (for CP and Sokolow-Lyon voltage), as well as separately for males and females (for the Solow-Lyon and CVs). The computer software SPSS version 18.0 (SPSS Inc, Chicago, IL, USA) was used for all analyses, and $\mathrm{P}<0.05$ was considered statistically significant.

\section{Results}

\section{Study Subjects}

The subjects' characteristics are shown in Table 1. The male and female subjects displayed similar mean ages, but systolic and diastolic blood pressures were significantly higher in the males than the females. Sokolow-Lyon ( $\mathrm{S}$ in lead V1 and R in lead V5) and CVs ( $\mathrm{S}$ in lead V3 and $\mathrm{R}$ in lead aVL) were significantly greater in males than in females. The distributions of CV in males and females, and that of unadjusted and sex-adjusted CP in females and males are shown Figure S1. In females, $\mathrm{CP}$ without adjustment for sex was smaller than that in males. When $0.6 \mathrm{mV}(6 \mathrm{~mm})$ was added to the $\mathrm{CV}$ in the calculation of females' $\mathrm{CP},{ }^{4}$ the 75 th and 95 th percentiles of CP became similar between males and females.

Follow-up

We followed up the subjects for a mean period of $140.9 \pm 30.7$ months $(1,432,728$ person-years) for mortality and $127.4 \pm 30.7$ months $(1,295,453$ person-years) for morbidity. During the follow-up period, there were 794 deaths from any cause, comprising 183 deaths from cardiovascular or stroke events (12 deaths from vascular disease, 76 deaths from cardiac disease, 95 deaths from cerebrovascular disease), 320 deaths from malignant disease, and 291 deaths from other causes (suicide, trauma, lung disease, liver disease, and infection). In addition, 422 subjects suffered their first cardiovascular or stroke event (70 cases of cardiovascular events, 362 cases of stroke events, 10 cases of both cardiovascular and stroke events; including 
A

Combined cardiovascular and stroke mortality in males

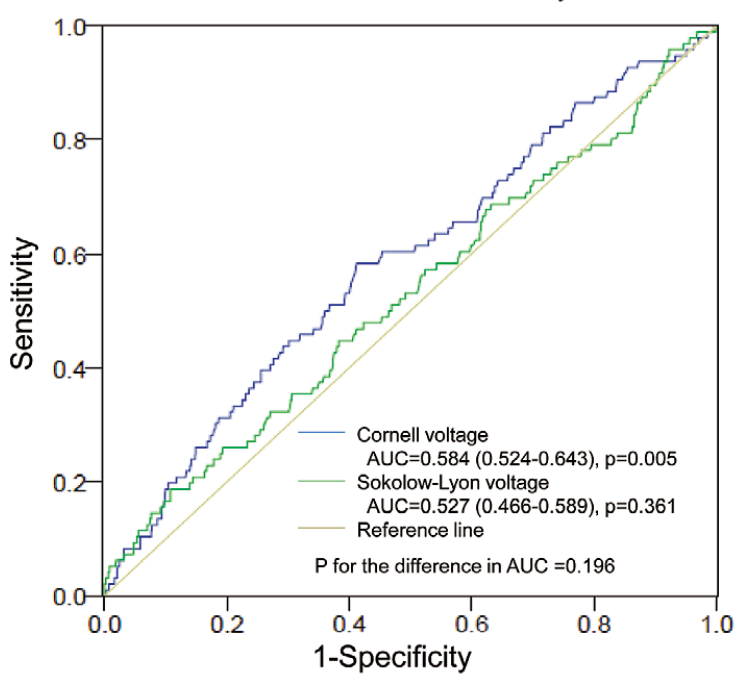

C

Combined cardiovascular and stroke morbidity in males

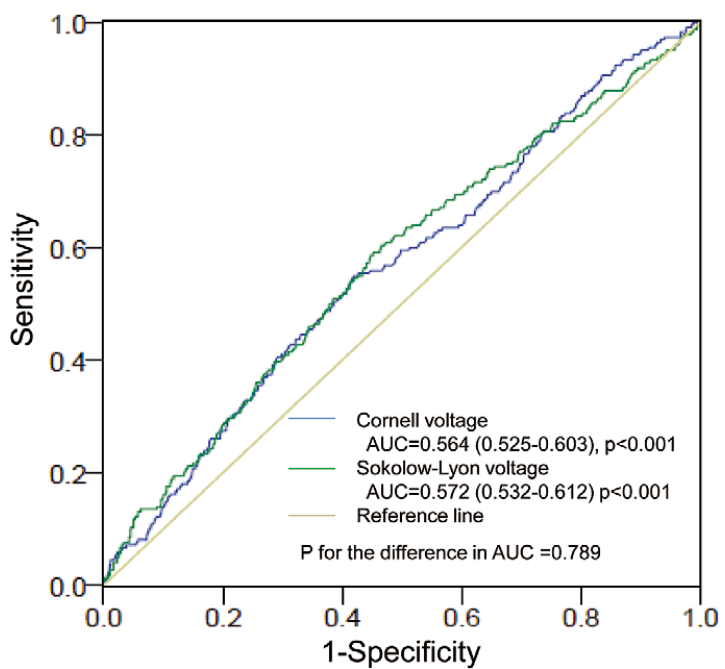

B

Combined cardiovascular and stroke mortality in females

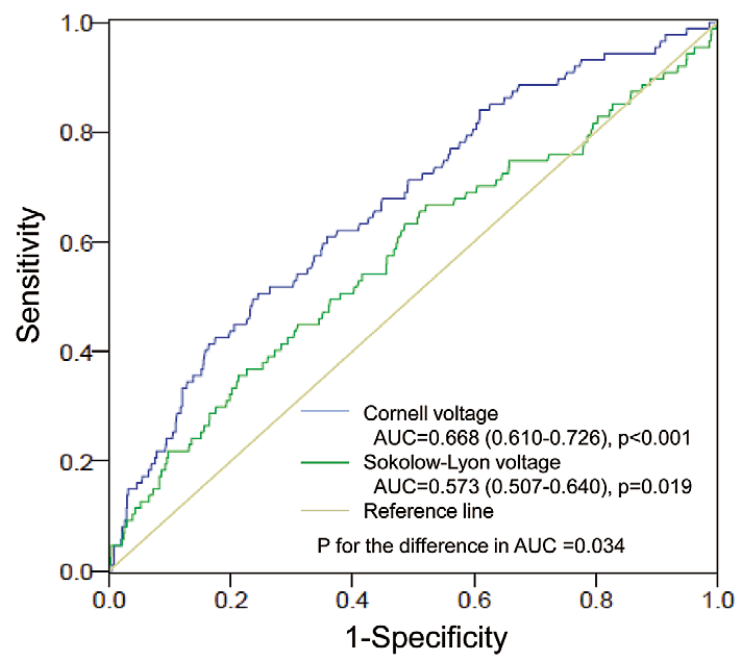

D

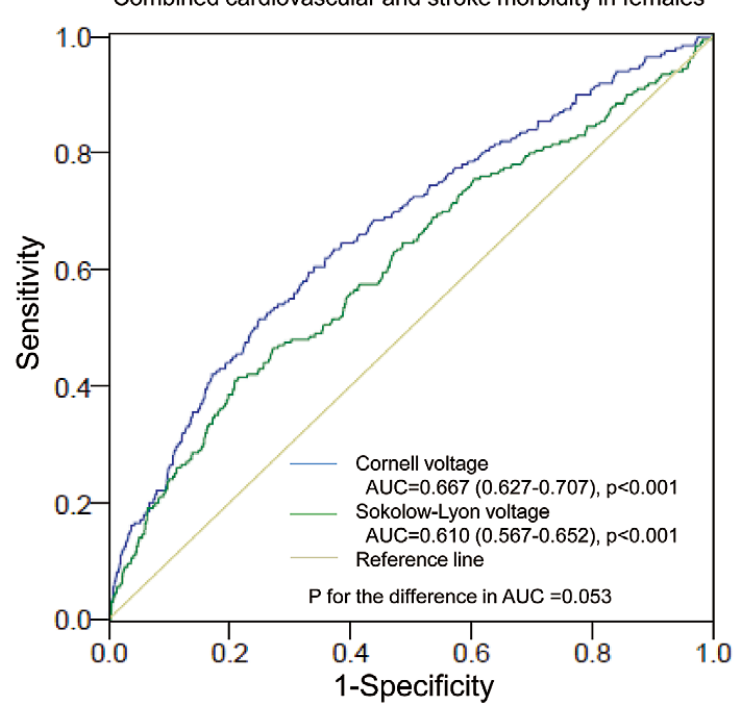

Figure 1. Receiver-operating curves of Cornell voltage for predicting combined cardiovascular and stroke mortality in males (A) and females (B) and cardiovascular and stroke morbidity in males (C) and females (D). Data are shown as mean values (95\% confidence intervals). AUC, area under the curve.

both fatal and nonfatal events).

\section{Analysis of Sokolow-Lyon and CVs as Continuous Variables} The risks of all-cause mortality, CCS mortality, and CCS morbidity associated with increases in the Sokolow-Lyon and CVs are shown separately for males and females in Table 2 . In males, multivariate analysis found that each $0.1 \mathrm{mV}(1 \mathrm{~mm})$ increase in the $\mathrm{CV}$ was associated with $4.0 \%$, and $2.2 \%$ increases in CCS mortality, and CCS morbidity, respectively. In females, multivariate analysis found that these risks increased by $5.8 \%$, and $5.6 \%$, respectively, with each $0.1 \mathrm{mV}(1 \mathrm{~mm})$ increase in the CV. Each $0.1 \mathrm{mV}(1 \mathrm{~mm})$ increase in the Sokolow-Lyon voltage was associated with $1.3 \%$, and $1.9 \%$ increase, respectively, in CCS mortality and morbidity in males, and $2.9 \%$ and
$2.8 \%$ increase, respectively, in CCS mortality and morbidity in females.

The results of a parallel analysis of the risks associated with each component of the Sokolow-Lyon voltage (ie, $\mathrm{S}$ in lead V1 and R in lead V5) and CV (ie, S in lead V3 and R in lead aVL) are shown in Table $\mathbf{S 1}$ (males and females).

\section{Cutoff Levels and the Risk of CCS Morbidity Separately in Males and Females}

The area under curve (AUC) values of the receiver-operating characteristic (ROC) curves of the Cornell and Sokolow-Lyon voltages for predicting CCS mortality and CCS morbidity are shown separately for males and females (Figure 1). In females, the AUC of the CV was greater than that of Sokolow- 


\begin{tabular}{|c|c|c|c|c|c|c|c|c|}
\hline \multirow{2}{*}{$\begin{array}{l}\text { Quintile of CV } \\
\text { Males }\end{array}$} & \multicolumn{4}{|c|}{ Univariate analysis } & \multicolumn{4}{|c|}{ Multivariate analysis } \\
\hline & HR & \multicolumn{2}{|c|}{$95 \% \mathrm{Cl}$} & $P$ value & HR & \multicolumn{2}{|c|}{$95 \% \mathrm{Cl}$} & $P$ value \\
\hline \multicolumn{9}{|l|}{ All-cause mortality } \\
\hline $\mathrm{Q} 1, \leq 1.03 \mathrm{mV}$ & Ref. & & & & Ref. & & & \\
\hline $\mathrm{Q} 2,1.04-1.35 \mathrm{mV}$ & 1.284 & 0.948 & 1.741 & 0.107 & 1.163 & 0.856 & 1.580 & 0.334 \\
\hline Q3, $1.36-1.64 \mathrm{mV}$ & 1.052 & 0.767 & 1.443 & 0.754 & 1.014 & 0.737 & 1.394 & 0.932 \\
\hline $\mathrm{Q} 4,1.65-2.03 \mathrm{mV}$ & 1.262 & 0.929 & 1.715 & 0.136 & 1.138 & 0.835 & 1.551 & 0.412 \\
\hline $\mathrm{Q} 5, \geq 2.04 \mathrm{mV}$ & 1.767 & 1.325 & 2.356 & $<0.001$ & 1.622 & 1.205 & 2.183 & 0.001 \\
\hline \multicolumn{9}{|l|}{ CCS mortality } \\
\hline $\mathrm{Q} 1, \leq 1.03 \mathrm{mV}$ & Ref. & & & & Ref. & & & \\
\hline $\mathrm{Q} 2,1.04-1.35 \mathrm{mV}$ & 1.636 & 0.794 & 3.371 & 0.182 & 1.376 & 0.664 & 2.853 & 0.390 \\
\hline Q3, $1.36-1.64 \mathrm{mV}$ & 0.997 & 0.448 & 2.220 & 0.995 & 0.850 & 0.380 & 1.905 & 0.694 \\
\hline $\mathrm{Q} 4,1.65-2.03 \mathrm{mV}$ & 1.839 & 0.905 & 3.738 & 0.092 & 1.473 & 0.718 & 3.022 & 0.290 \\
\hline $\mathrm{Q} 5, \geq 2.04 \mathrm{mV}$ & 2.713 & 1.389 & 5.302 & 0.003 & 2.094 & 1.047 & 4.189 & 0.037 \\
\hline \multicolumn{9}{|l|}{ CCS morbidity } \\
\hline $\mathrm{Q} 1, \leq 1.03 \mathrm{mV}$ & Ref. & & & & Ref. & & & \\
\hline $\mathrm{Q} 2,1.04-1.35 \mathrm{mV}$ & 1.589 & 1.003 & 2.516 & 0.049 & 1.335 & 0.840 & 2.122 & 0.222 \\
\hline Q3, $1.36-1.64 \mathrm{mV}$ & 0.988 & 0.596 & 1.639 & 0.962 & 0.860 & 0.517 & 1.431 & 0.561 \\
\hline $\mathrm{Q} 4,1.65-2.03 \mathrm{mV}$ & 1.859 & 1.188 & 2.910 & 0.007 & 1.472 & 0.936 & 2.315 & 0.095 \\
\hline $\mathrm{Q} 5, \geq 2.04 \mathrm{mV}$ & 2.076 & 1.336 & 3.226 & 0.001 & 1.402 & 0.888 & 2.212 & 0.147 \\
\hline \multicolumn{9}{|l|}{ Stroke event } \\
\hline $\mathrm{Q} 1, \leq 1.03 \mathrm{mV}$ & Ref. & & & & Ref. & & & \\
\hline $\mathrm{Q} 2,1.04-1.35 \mathrm{mV}$ & 1.599 & 0.935 & 2.734 & 0.086 & 1.360 & 0.793 & 2.334 & 0.264 \\
\hline Q3, $1.36-1.64 \mathrm{mV}$ & 1.171 & 0.664 & 2.067 & 0.585 & 1.021 & 0.576 & 1.808 & 0.944 \\
\hline $\mathrm{Q} 4,1.65-2.03 \mathrm{mV}$ & 2.150 & 1.291 & 3.580 & 0.003 & 1.730 & 1.033 & 2.899 & 0.037 \\
\hline $\mathrm{Q} 5, \geq 2.04 \mathrm{mV}$ & 2.334 & 1.409 & 3.867 & 0.001 & 1.597 & 0.948 & 2.689 & 0.079 \\
\hline \multicolumn{9}{|l|}{ Ml event } \\
\hline $\mathrm{Q} 1, \leq 1.03 \mathrm{mV}$ & Ref. & & & & Ref. & & & \\
\hline $\mathrm{Q} 2,1.04-1.35 \mathrm{mV}$ & 1.339 & 0.587 & 3.053 & 0.488 & 1.107 & 0.481 & 2.550 & 0.811 \\
\hline Q3, 1.36-1.64 mV & 0.396 & 0.124 & 1.262 & 0.117 & 0.352 & 0.110 & 1.131 & 0.080 \\
\hline Q4, 1.65-2.03mV & 1.151 & 0.489 & 2.711 & 0.748 & 0.864 & 0.362 & 2.065 & 0.743 \\
\hline $\mathrm{Q} 5, \geq 2.04 \mathrm{mV}$ & 1.181 & 0.502 & 2.783 & 0.703 & 0.784 & 0.321 & 1.913 & 0.592 \\
\hline \multicolumn{9}{|l|}{ Females } \\
\hline \multicolumn{9}{|l|}{ All-cause mortality } \\
\hline $\mathrm{Q} 1, \leq 0.83 \mathrm{mV}$ & Ref. & & & & Ref. & & & \\
\hline $\mathrm{Q} 2,0.84-1.11 \mathrm{mV}$ & 1.201 & 0.806 & 1.788 & 0.368 & 1.081 & 0.725 & 1.614 & 0.702 \\
\hline Q3, $1.12-1.37 \mathrm{mV}$ & 1.155 & 0.772 & 1.729 & 0.483 & 0.790 & 0.525 & 1.189 & 0.258 \\
\hline Q4, 1.38-1.70mV & 1.479 & 1.009 & 2.168 & 0.045 & 0.951 & 0.644 & 1.404 & 0.800 \\
\hline $\mathrm{Q} 5, \geq 1.71 \mathrm{mV}$ & 2.297 & 1.610 & 3.277 & $<0.001$ & 1.207 & 0.832 & 1.751 & 0.321 \\
\hline CCS mortality & & & & & & & & \\
\hline $\mathrm{Q} 1, \leq 0.83 \mathrm{mV}$ & Ref. & & & & Ref. & & & \\
\hline $\mathrm{Q} 2,0.84-1.11 \mathrm{mV}$ & 2.350 & 0.828 & 6.672 & 0.108 & 2.161 & 0.757 & 6.164 & 0.150 \\
\hline Q3, $1.12-1.37 \mathrm{mV}$ & 2.993 & 1.088 & 8.235 & 0.034 & 1.682 & 0.604 & 4.685 & 0.320 \\
\hline $\mathrm{Q} 4,1.38-1.70 \mathrm{mV}$ & 3.191 & 1.169 & 8.711 & 0.024 & 1.769 & 0.641 & 4.887 & 0.271 \\
\hline $\mathrm{Q} 5, \geq 1.71 \mathrm{mV}$ & 7.296 & 2.863 & 18.594 & $<0.001$ & 3.015 & 1.155 & 7.870 & 0.024 \\
\hline CCS morbidity & & & & & & & & \\
\hline $\mathrm{Q} 1, \leq 0.83 \mathrm{mV}$ & Ref. & & & & Ref. & & & \\
\hline Q2, 0.84-1.11mV & 1.176 & 0.650 & 2.129 & 0.592 & 0.989 & 0.545 & 1.795 & 0.970 \\
\hline Q3, $1.12-1.37 \mathrm{mV}$ & 1.348 & 0.756 & 2.403 & 0.312 & 0.862 & 0.481 & 1.547 & 0.619 \\
\hline $\mathrm{Q} 4,1.38-1.70 \mathrm{mV}$ & 2.104 & 1.235 & 3.583 & 0.006 & 1.206 & 0.702 & 2.072 & 0.497 \\
\hline $\mathrm{Q} 5, \geq 1.71 \mathrm{mV}$ & 4.441 & 2.729 & 7.229 & $<0.001$ & 1.901 & 1.146 & 3.155 & 0.013 \\
\hline Stroke event & & & & & & & & \\
\hline $\mathrm{Q} 1, \leq 0.83 \mathrm{mV}$ & Ref. & & & & Ref. & & & \\
\hline $\mathrm{Q} 2,0.84-1.11 \mathrm{mV}$ & 1.031 & 0.551 & 1.933 & 0.923 & 0.872 & 0.464 & 1.638 & 0.670 \\
\hline Q3, $1.12-1.37 \mathrm{mV}$ & 1.262 & 0.691 & 2.304 & 0.449 & 0.809 & 0.440 & 1.486 & 0.494 \\
\hline $\mathrm{Q} 4,1.38-1.70 \mathrm{mV}$ & 2.112 & 1.223 & 3.646 & 0.007 & 1.218 & 0.699 & 2.123 & 0.486 \\
\hline $\mathrm{Q} 5, \geq 1.71 \mathrm{mV}$ & 4.226 & 2.558 & 6.982 & $<0.001$ & 1.817 & 1.078 & 3.064 & 0.025 \\
\hline
\end{tabular}

(Table 3 continued the next page.) 


\begin{tabular}{|c|c|c|c|c|c|c|c|c|}
\hline \multirow[b]{2}{*}{ Quintile of CV } & \multicolumn{4}{|c|}{ Univariate analysis } & \multicolumn{4}{|c|}{ Multivariate analysis } \\
\hline & HR & \multicolumn{2}{|c|}{$95 \% \mathrm{Cl}$} & $P$ value & HR & \multicolumn{2}{|c|}{$95 \% \mathrm{Cl}$} & $P$ value \\
\hline \multicolumn{9}{|l|}{ Ml event } \\
\hline $\mathrm{Q} 1, \leq 0.83 \mathrm{mV}$ & Ref. & & & & Ref. & & & \\
\hline $\mathrm{Q} 2,0.84-1.11 \mathrm{mV}$ & 1.964 & 0.360 & 10.722 & 0.436 & 1.612 & 0.292 & 8.892 & 0.584 \\
\hline Q3, $1.12-1.37 \mathrm{mV}$ & 1.493 & 0.249 & 8.934 & 0.661 & 0.959 & 0.157 & 5.838 & 0.963 \\
\hline $\mathrm{Q} 4,1.38-1.70 \mathrm{mV}$ & 1.984 & 0.363 & 10.831 & 0.429 & 1.054 & 0.188 & 5.900 & 0.952 \\
\hline $\mathrm{Q} 5, \geq 1.71 \mathrm{mV}$ & 4.065 & 0.863 & 19.143 & 0.076 & 1.591 & 0.319 & 7.944 & 0.571 \\
\hline
\end{tabular}

In the multivariate adjusted model, age, sex, body mass index, alcohol drinking habit, smoking status, presence of hyperlipidemia, status of diabetes, systolic blood pressure, and antihypertensive medication use were also entered into the Cox regression analysis.

MI, myocardial infarction; Ref., reference. Other abbreviations as in Table 2.

A

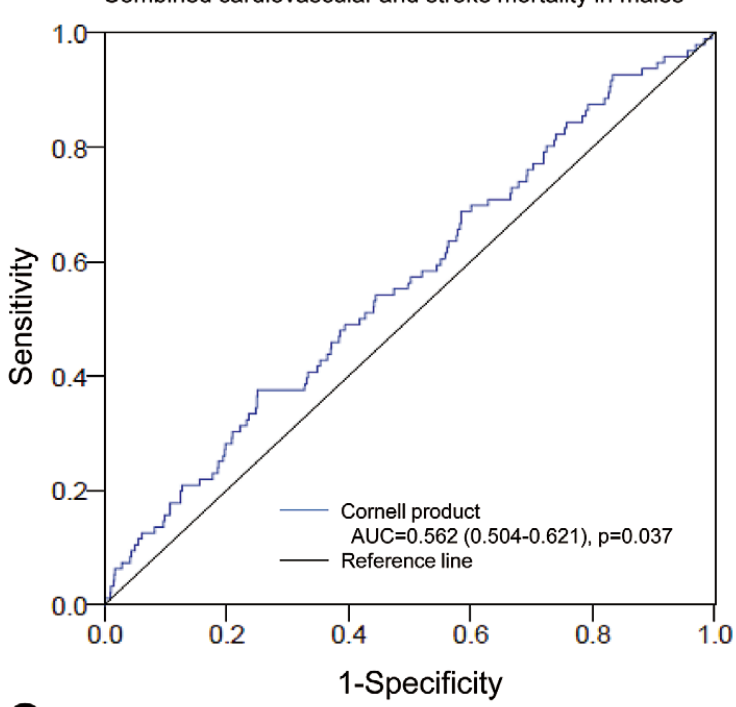

C

Combined cardiovascular and stroke morbidity in males

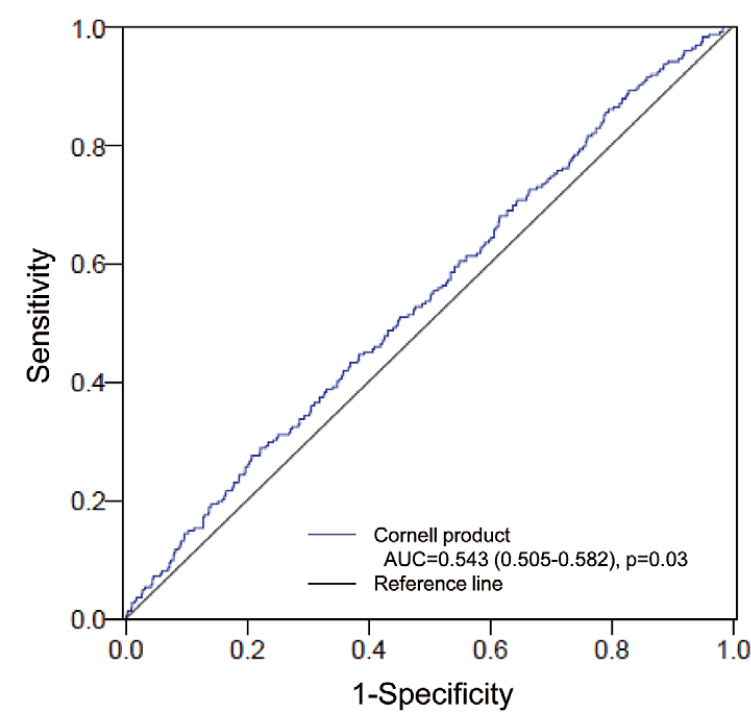

B
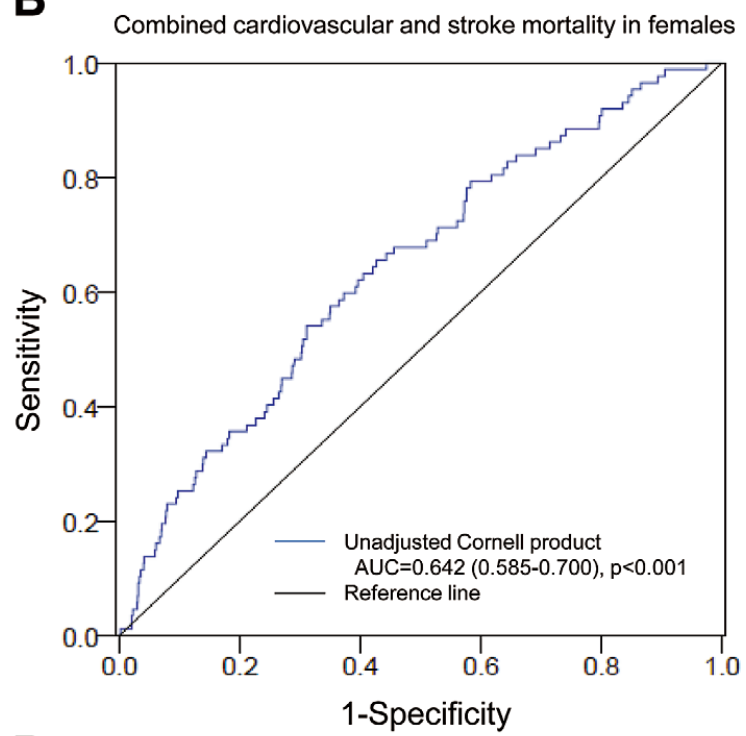

D
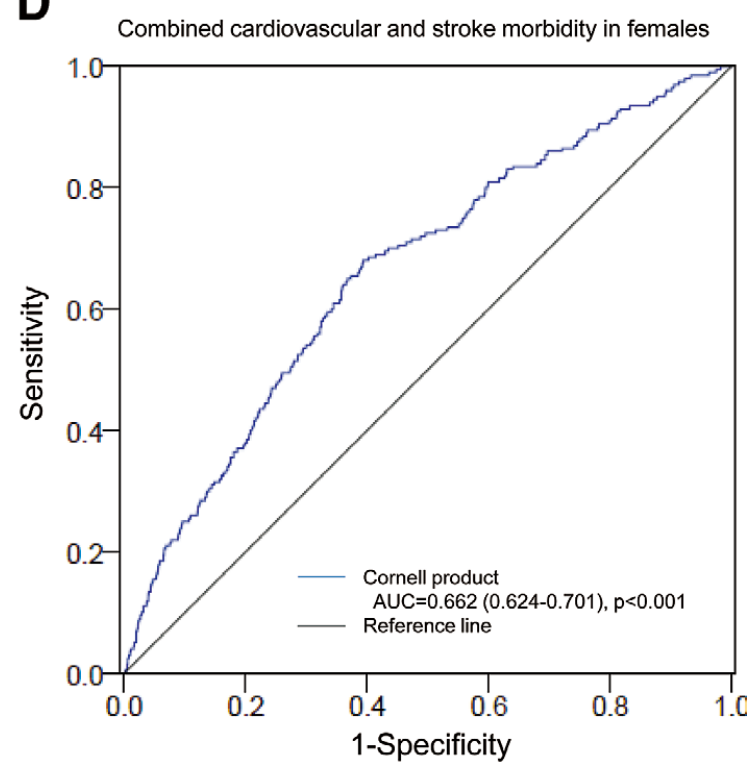

Figure 2. Receiver-operating curve of Cornell product for predicting combined cardiovascular and stroke mortality in males (A) and females (B) and cardiovascular and stroke morbidity in males (C) and females (D). Data are shown as mean values (95\% confidence intervals). AUC, area under the curve. 
A

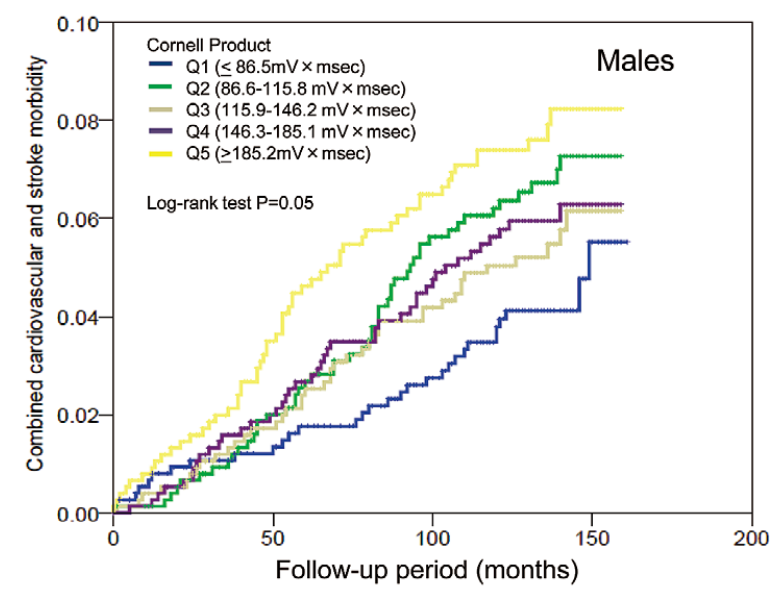

N. at risk

$\begin{array}{lllll}\text { Q1 } & 765 & 715 & 673 & 125 \\ \text { Q2 } & 766 & 723 & 663 & 114 \\ \text { Q3 } & 766 & 731 & 684 & 132 \\ \text { Q4 } & 766 & 727 & 672 & 118 \\ \text { Q5 } & 766 & 693 & 633 & 118\end{array}$

C

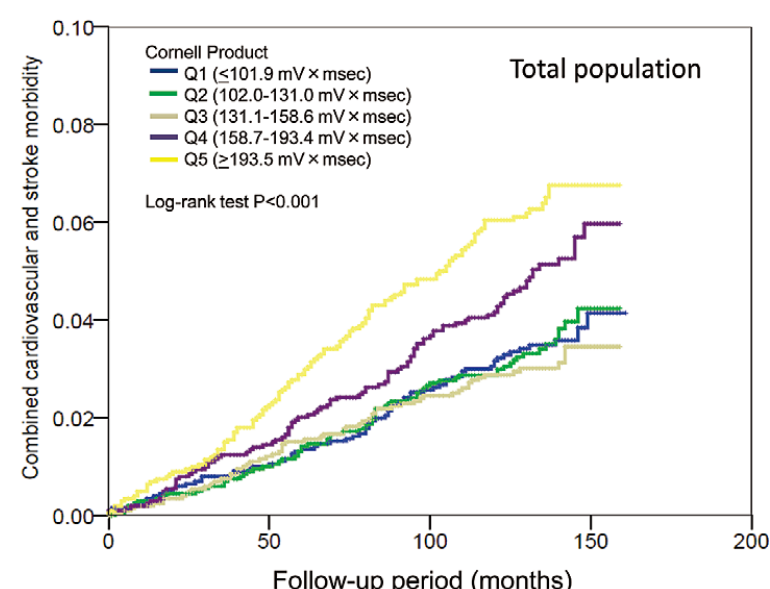

N. at risk

$\begin{array}{ll}\text { Q1 } & 2034 \\ \text { Q2 } & 2037 \\ \text { Q3 } & 2033\end{array}$

Q3 2033

Q5 2034

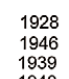

1928
1946
1939
1940
1902

1833
1844
1843
1825
1763

B

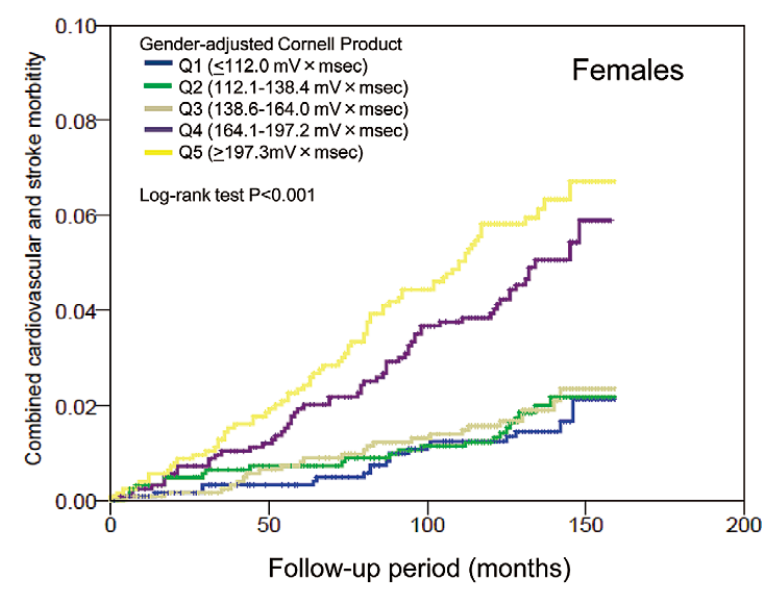

\section{D}

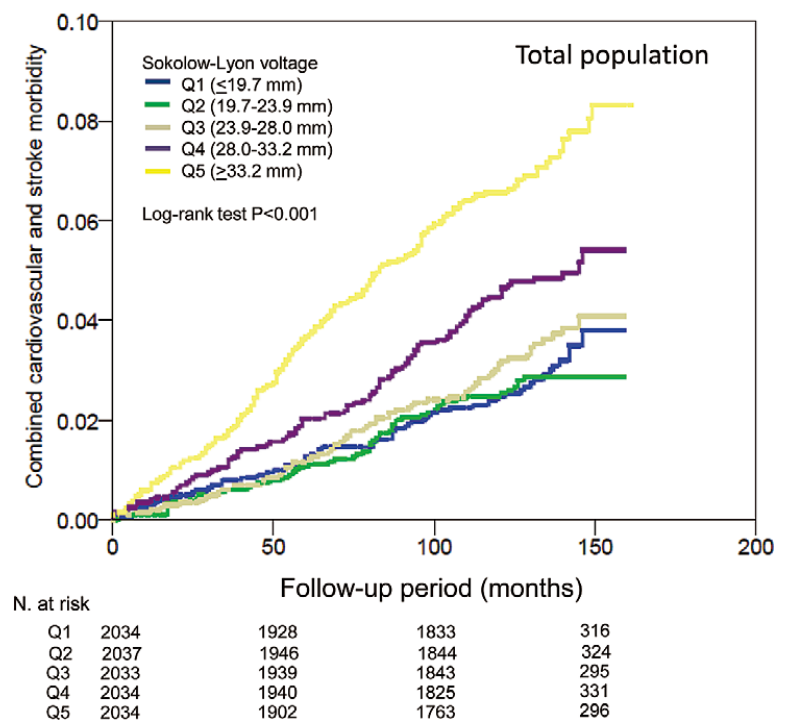

Figure 3. Kaplan-Meier curves for combined cardiovascular and stroke morbidity in the subjects with quintile of males' Cornell product (A), females' Cornell product (B), Cornell product in total population (C), and Sokolow-Lyon voltage in total population (D). Differences between the prognostic values of each quintile were calculated using the log-rank test. $P<0.05$ was considered statistically significant.

Lyon voltage, but in males, the AUC of the CV was similar to that of the Sokolow-Lyon voltage. The AUC of the CV in males was only marginally significant $0.584(\mathrm{P}=0.005)$. In the quintile-based multivariate-adjusted model for males, the highest quintile of the $\mathrm{CV}(>2.04 \mathrm{mV})$ was associated with an increased risk of CCS mortality and the 4th $(1.65-2.03 \mathrm{mV})$ and highest $(\geq 2.04 \mathrm{mV})$ quintile of $\mathrm{CV}$ was associated with an increased risk of stroke events (Table 3 ). In the parallel analysis for females, the highest quintile of the $\mathrm{CV}(>1.71 \mathrm{mV})$ was associated with an increased risk of CCS mortality and morbidity (Table 3). In both males and females, the highest quin- tiles of the CV associated with CCS risks were lower than the risk levels shown in the JSH2009 guideline. ${ }^{4}$

\section{Unadjusted and Gender-Adjusted CP and the Risk of CCS Morbidity Separately in Males and Females}

Because there were no data that showed whether the adjustment of $0.6 \mathrm{mV}(6 \mathrm{~mm})$ in the calculation of females' CP was appropriate in a Japanese population, we evaluated CP cutoff levels without adjustment for sex separately in males and females. In males, the AUCs of the CP for predicting CCS mortality $(0.562, \mathrm{P}=0.037)$ and morbidity $(0.543, \mathrm{P}=0.03)$ were only 


\begin{tabular}{|c|c|c|c|c|c|c|c|c|}
\hline \multirow{2}{*}{ All-cause mortality } & \multicolumn{4}{|c|}{$\mathrm{CP}$ per $10.0 \mathrm{mV} \times \mathrm{ms}$} & \multicolumn{4}{|c|}{ Sokolow-Lyon voltage per $0.1 \mathrm{mV}$} \\
\hline & \multirow{2}{*}{$\begin{array}{c}\text { HR } \\
1.023\end{array}$} & \multicolumn{2}{|c|}{$95 \% \mathrm{Cl}$} & \multirow{2}{*}{$\begin{array}{l}\text { P value } \\
<0.001\end{array}$} & \multirow{2}{*}{$\begin{array}{c}\mathbf{H R} \\
1.030\end{array}$} & \multicolumn{2}{|c|}{$95 \% \mathrm{Cl}$} & \multirow{2}{*}{$\begin{array}{l}\text { P value } \\
<0.001\end{array}$} \\
\hline Unadjusted & & 1.011 & 1.034 & & & 1.021 & 1.038 & \\
\hline Age and gender adjusted & 1.025 & 1.013 & 1.036 & $<0.001$ & 1.011 & 1.003 & 1.019 & 0.006 \\
\hline Multivariate adjusted & 1.025 & 1.013 & 1.037 & $<0.001$ & 1.009 & 1.000 & 1.017 & 0.041 \\
\hline \multicolumn{9}{|l|}{ CCS mortality } \\
\hline Unadjusted & 1.049 & 1.027 & 1.071 & $<0.001$ & 1.040 & 1.024 & 1.057 & $<0.001$ \\
\hline Age and gender adjusted & 1.047 & 1.024 & 1.070 & $<0.001$ & 1.025 & 1.008 & 1.041 & 0.003 \\
\hline Multivariate adjusted & 1.040 & 1.016 & 1.064 & 0.001 & 1.020 & 1.004 & 1.038 & 0.017 \\
\hline \multicolumn{9}{|l|}{ CCS morbidity } \\
\hline Unadjusted & 1.047 & 1.033 & 1.062 & $<0.001$ & 1.047 & 1.036 & 1.058 & $<0.001$ \\
\hline Age and gender adjusted & 1.045 & 1.030 & 1.060 & $<0.001$ & 1.033 & 1.022 & 1.044 & $<0.001$ \\
\hline Multivariate adjusted & 1.030 & 1.015 & 1.046 & $<0.001$ & 1.023 & 1.012 & 1.035 & $<0.001$ \\
\hline \multicolumn{9}{|l|}{ Stroke event } \\
\hline Unadjusted & 1.052 & 1.037 & 1.068 & $<0.001$ & 1.045 & 1.033 & 1.057 & $<0.001$ \\
\hline Age and gender adjusted & 1.048 & 1.033 & 1.064 & $<0.001$ & 1.033 & 1.021 & 1.044 & $<0.001$ \\
\hline Multivariate adjusted & 1.034 & 1.018 & 1.051 & $<0.001$ & 1.023 & 1.011 & 1.035 & $<0.001$ \\
\hline \multicolumn{9}{|l|}{ MI event } \\
\hline Unadjusted & 1.008 & 0.968 & 1.049 & 0.707 & 1.052 & 1.027 & 1.078 & $<0.001$ \\
\hline Age and gender adjusted & 1.018 & 0.980 & 1.057 & 0.362 & 1.029 & 1.004 & 1.055 & 0.025 \\
\hline Multivariate adjusted & 1.001 & 0.963 & 1.041 & 0.948 & 1.019 & 0.993 & 1.045 & 0.157 \\
\hline
\end{tabular}

$\mathrm{CP}$ was calculated after adding $6 \mathrm{~mm}$ to the $\mathrm{CP}$ for women. In the multivariate adjusted model, age, sex, body mass index, alcohol drinking habit, smoking status, presence of hyperlipidemia, status of diabetes, systolic blood pressure, and antihypertensive medication use were also entered into the Cox regression analysis.

Abbreviations as in Tables 2,3.

marginally significant (Figure 2). The Kaplan-Meier curve of males' CP quintiles for predicting CCS morbidity is shown in Figure 3A. In the quintile-based analysis of CP (Table S2), the highest quintile of $\mathrm{CP}(>185.2 \mathrm{mV} \times \mathrm{ms})$ was associated with CCS mortality risk.

In females, the AUCs of the CP for predicting CCS mortality and morbidity were greater than those in males. The KaplanMeier curve of females' CP quintiles for predicting CCS morbidity is shown in Figure 3B. The 4th (unadjusted CP, 114.1144.0 $\mathrm{mV} \times \mathrm{ms}$; gender-adjusted CP, 164.1-197.2 mV×ms) and highest (unadjusted $\mathrm{CP}, \geq 144.1 \mathrm{mV} \times \mathrm{ms}$; gender-adjusted $\mathrm{CP}$ $\geq 197.3 \mathrm{mV} \times \mathrm{ms}$ ) quintile of the $\mathrm{CP}$ were associated with increased CCS morbidity (Table S2).

\section{Significance of CP and Sokolow-Lyon Voltage in All Subjects}

In the whole study population, when the $\mathrm{CP}$ was subjected to multivariate analysis as a continuous variable, each $10 \mathrm{mV} \times \mathrm{ms}$ $(100 \mathrm{~mm} \times \mathrm{ms})$ increase was found to be associated with $4.0 \%$ and $3.0 \%$ increases in the risks of CCS mortality and CCS morbidity, respectively (Table 4 ). In the whole study population, each $0.1 \mathrm{mV}(1 \mathrm{~mm})$ increase in the Sokolow-Lyon voltage was associated with a $2.0 \%$ and $2.3 \%$ increases in the risks of CCS mortality and CCS morbidity, respectively (Table 4).

Kaplan-Meier curves of the relationships between each CP quintile and CCS morbidity in the whole study population are shown in Figure 3C. The risks of CCS morbidity were increased in the subjects with CPs that were in the 4th or 5th quintiles. Even after adjusting for conventional confounding cardiovascular risk factors in the Cox proportional hazards model, the subjects with CPs in the 4th (158.7-193.4 $\mathrm{mV \times ms)}$ or 5th quintile $(\geq 193.5 \mathrm{mV} \times \mathrm{ms})$ were significantly more likely to suffer CCS morbidity than those with CPs that fell within the lowest quintile $(\mathrm{CP}<101.9 \mathrm{mV} \times \mathrm{ms})$ (Table S3). Therefore, a CP threshold of approximately $160.0 \mathrm{mV} \times \mathrm{ms}$ was found to be associated with significant increases in CCS morbidity in this study. When the subjects were stratified into 3 groups using cutoff levels of 160.0 and $244.0 \mathrm{mV} \times \mathrm{ms}$, the subjects with CPs between 160.0 and $244.0 \mathrm{mV} \times \mathrm{ms}$ had a 1.32 -fold higher risk of CCS mortality than those with $\mathrm{CP}<160.0 \mathrm{mV} \times \mathrm{ms}$ (Table 5).

Kaplan-Meier curves of the relationships between each Sokolow-Lyon voltage quintile and CCS morbidity in the whole study population are shown in Figure 3D. The risks of CCS morbidity were marginally increased even in subjects with a Sokolow-Lyon voltage in the 4th quintile (Table S4). A Sokolow-Lyon voltage threshold of approximately $3.0 \mathrm{mV}$ $(30 \mathrm{~mm})$ seemed to be associated with significant increases in CCS morbidity in this study. When the subjects were stratified into 3 groups using cutoff levels of 3.0 and $3.8 \mathrm{mV}$, the subjects with Sokolow-Lyon voltage between 3.0 and $3.8 \mathrm{mV}$ had a 1.46-fold higher risk of CCS morbidity than those with Sokolow-Lyon voltage $<3.0 \mathrm{mV}$ (Table 5).

\section{Discussion}

In the present study, the Sokolow-Lyon voltage, $\mathrm{CV}$, and $\mathrm{CP}$ as continuous variables were associated with significantly increased risks of CCS morbidity. Subjects with the highest quintile of CV had an increased risk of CCS mortality or morbidity, and the levels were $2.04 \mathrm{mV}$ for males and $1.71 \mathrm{mV}$ for females. The CP predicted CCS morbidity even at levels between 160.0 and $244.0 \mathrm{mV} \times \mathrm{ms}$ in the total population that included both males and females, but it was largely attributable to the CCS morbidity in females. The Sokolow-Lyon voltage predicted 


\begin{tabular}{|c|c|c|c|c|c|c|c|c|c|c|c|}
\hline \multirow{2}{*}{ CP } & \multirow{2}{*}{$\begin{array}{l}\text { N. of } \\
\text { event }\end{array}$} & \multirow{2}{*}{$\begin{array}{c}\text { Crude } \\
\text { incidence (\%) }\end{array}$} & \multirow{2}{*}{$\begin{array}{l}\text { N. per } 1,000 \\
\text { person-years }\end{array}$} & \multicolumn{4}{|c|}{ Univariate analysis } & \multicolumn{4}{|c|}{ Multivariate analysis } \\
\hline & & & & HR & \multicolumn{2}{|c|}{$95 \% \mathrm{Cl}$} & $P$ value & HR & \multicolumn{2}{|c|}{$95 \% \mathrm{Cl}$} & $P$ value \\
\hline \multicolumn{12}{|l|}{ All-cause mortality } \\
\hline$<160.0 \mathrm{mV} \times \mathrm{ms}$ & 442 & 6.2 & 6.02 & Ref. & & & & Ref. & & & \\
\hline $160.0-244.0 \mathrm{mV} \times \mathrm{ms}$ & 266 & 7.1 & 6.83 & 1.156 & 0.991 & 1.348 & 0.065 & 1.205 & 1.028 & 1.413 & 0.022 \\
\hline$\geq 244.0 \mathrm{mV} \times \mathrm{ms}$ & 86 & 13.0 & 12.27 & 2.036 & 1.607 & 2.579 & $<0.001$ & 1.829 & 1.434 & 2.334 & $<0.001$ \\
\hline \multicolumn{12}{|l|}{ CCS mortality } \\
\hline$<160.0 \mathrm{mV} \times \mathrm{ms}$ & 93 & 1.0 & 1.27 & Ref. & & & & Ref. & & & \\
\hline $160.0-244.0 \mathrm{mV} \times \mathrm{ms}$ & 66 & 1.6 & 1.69 & 1.345 & 0.976 & 1.853 & 0.070 & 1.207 & 0.866 & 1.684 & 0.267 \\
\hline$\geq 244.0 \mathrm{mV} \times \mathrm{ms}$ & 24 & 2.7 & 3.42 & 2.812 & 1.792 & 4.413 & $<0.001$ & 2.105 & 1.317 & 3.363 & 0.002 \\
\hline \multicolumn{12}{|l|}{ CCS morbidity } \\
\hline$<160.0 \mathrm{mV} \times \mathrm{ms}$ & 205 & 3.3 & 3.08 & Ref. & & & & Ref. & & & \\
\hline $160.0-244.0 \mathrm{mV} \times \mathrm{ms}$ & 164 & 5.1 & 4.66 & 1.527 & 1.241 & 1.878 & $<0.001$ & 1.324 & 1.069 & 1.640 & 0.010 \\
\hline$\geq 244.0 \mathrm{mV} \times \mathrm{ms}$ & 53 & 8.7 & 8.44 & 2.732 & 2.014 & 3.706 & $<0.001$ & 1.809 & 1.321 & 2.479 & $<0.001$ \\
\hline \multicolumn{12}{|l|}{ Stroke event } \\
\hline$<160.0 \mathrm{mV} \times \mathrm{ms}$ & 171 & 2.8 & 2.57 & Ref. & & & & Ref. & & & \\
\hline $160.0-244.0 \mathrm{mV} \times \mathrm{ms}$ & 141 & 4.2 & 3.99 & 1.575 & 1.257 & 1.972 & $<0.001$ & 1.339 & 1.061 & 1.690 & 0.014 \\
\hline$\geq 244.0 \mathrm{mV} \times \mathrm{ms}$ & 50 & 7.9 & 7.94 & 3.097 & 2.252 & 4.259 & $<0.001$ & 2.030 & 1.461 & 2.822 & $<0.001$ \\
\hline \multicolumn{12}{|l|}{ Ml event } \\
\hline$<160.0 \mathrm{mV} \times \mathrm{ms}$ & 40 & 0.6 & 0.60 & Ref. & & & & Ref. & & & \\
\hline $160.0-244.0 \mathrm{mV} \times \mathrm{ms}$ & 27 & 0.8 & 0.76 & 1.276 & 0.783 & 2.080 & 0.327 & 1.257 & 0.758 & 2.084 & 0.375 \\
\hline$\geq 244.0 \mathrm{mV} \times \mathrm{ms}$ & 3 & 0.5 & 0.46 & 0.779 & 0.241 & 2.519 & 0.677 & 0.564 & 0.171 & 1.854 & 0.345 \\
\hline \multicolumn{12}{|l|}{ Sokolow-Lyon voltage } \\
\hline \multicolumn{12}{|l|}{ All-cause mortality } \\
\hline$<3.0 \mathrm{mV}$ & 476 & 6.8 & 5.80 & Ref. & & & & Ref. & & & \\
\hline $3.0-3.8 \mathrm{mV}$ & 199 & 8.8 & 7.53 & 1.310 & 1.108 & 1.549 & 0.002 & 1.034 & 0.872 & 1.226 & 0.698 \\
\hline$\geq 3.8 \mathrm{mV}$ & 119 & 12.6 & 10.94 & 1.940 & 1.584 & 2.377 & $<0.001$ & 1.216 & 0.985 & 1.502 & 0.069 \\
\hline \multicolumn{12}{|l|}{ CCS mortality } \\
\hline$<3.0 \mathrm{mV}$ & 105 & 1.5 & 1.28 & Ref. & & & & Ref. & & & \\
\hline $3.0-3.8 \mathrm{mV}$ & 47 & 2.1 & 1.78 & 1.407 & 0.993 & 1.994 & 0.055 & 1.124 & 0.788 & 1.604 & 0.519 \\
\hline$\geq 3.8 \mathrm{mV}$ & 31 & 3.3 & 2.85 & 2.329 & 1.557 & 3.484 & $<0.001$ & 1.523 & 0.999 & 2.322 & 0.051 \\
\hline \multicolumn{12}{|l|}{ CCS morbidity } \\
\hline$<3.0 \mathrm{mV}$ & 216 & 3.1 & 2.90 & Ref. & & & & Ref. & & & \\
\hline $3.0-3.8 \mathrm{mV}$ & 130 & 5.8 & 5.44 & 1.883 & 1.511 & 2.345 & $<0.001$ & 1.457 & 1.165 & 1.824 & 0.001 \\
\hline$\geq 3.8 \mathrm{mV}$ & 76 & 8.0 & 7.77 & 2.767 & 2.129 & 3.597 & $<0.001$ & 1.674 & 1.272 & 2.202 & $<0.001$ \\
\hline \multicolumn{12}{|l|}{ Stroke event } \\
\hline$<3.0 \mathrm{mV}$ & 185 & 2.7 & 2.48 & Ref. & & & & Ref. & & & \\
\hline $3.0-3.8 \mathrm{mV}$ & 114 & 5.1 & 4.77 & 1.929 & 1.524 & 2.443 & $<0.001$ & 1.510 & 1.186 & 1.921 & 0.001 \\
\hline$\geq 3.8 \mathrm{mV}$ & 63 & 6.6 & 6.44 & 2.668 & 2.002 & 3.554 & $<0.001$ & 1.665 & 1.234 & 2.247 & 0.001 \\
\hline Ml event & & & & & & & & & & & \\
\hline$<3.0 \mathrm{mV}$ & 37 & 0.5 & 0.49 & Ref. & & & & Ref. & & & \\
\hline $3.0-3.8 \mathrm{mV}$ & 20 & 0.9 & 0.82 & 1.670 & 0.969 & 2.877 & 0.065 & 1.145 & 0.658 & 1.992 & 0.632 \\
\hline$\geq 3.8 \mathrm{mV}$ & 13 & 1.4 & 1.30 & 2.655 & 1.411 & 4.994 & 0.002 & 1.293 & 0.666 & 2.510 & 0.448 \\
\hline
\end{tabular}

Statistical analysis was performed using a Cox hazard model. In the multivariate-adjusted model, conventional risk factors of age, sex, body mass index, alcohol drinking habit, smoking status, presence of hyperlipidemia, status of diabetes, systolic blood pressure, and antihypertensive medication use were also entered into the model.

Abbreviations as in Tables 2,3.

CCS morbidity even at levels between 3.0 and $3.8 \mathrm{mV}$. These results suggested that the $\mathrm{CV}$ and $\mathrm{CP}$ and Sokolow-Lyon voltage predicted future CCS morbidity at even lower levels than those described in the JSH2009 guideline ${ }^{4}$.

The mean CV in the present study was lower than that found in the Framingham study, ${ }^{10}$ in which the mean CV was $1.95 \mathrm{mV}$ for males and $1.99 \mathrm{mV}$ for females, but was comparable to the values reported in a previous study of Japanese patients $(1.34 \pm 0.59 \mathrm{mV}$ in normotensive subjects and $1.96 \pm 0.79 \mathrm{mV}$ in untreated hypertensive subjects). ${ }^{22}$ It was also reported that Korean patients displayed lower CV cutoff levels for detecting echocardiogram LVH (2.0 mV in males and $1.6 \mathrm{mV}$ in females) compared with Western populations ${ }^{23}$ and the levels were close to the cutoff levels of CV for predicting CCS risks in this 
study. Moreover, the CV levels that were associated with significantly increased risks of CCS morbidity in this study were lower than those observed in the Framingham study, in which the highest $\mathrm{CV}$ quartile $(\geq 2.4 \mathrm{mV})$ was significantly associated with cardiovascular mortality compared with the lowest $\mathrm{CV}$ quartile. Although no data regarding echocardiogram or cardiac MRI-diagnosed LVH were obtained in this study, Asian subjects might tend to have lower CVs, and hence require lower thresholds for detecting anatomical LVH than Western subjects, and this might lead to lower cutoff levels of CV for predicting cardiovascular and stroke events.

The predictive values of $\mathrm{CV}$ and $\mathrm{CP}$ for CCS morbidity were greater in females than in males. In males, the AUC of the $\mathrm{CP}$ for predicting CCS mortality and morbidity was smaller than for females, and it was difficult to determine a threshold of the $\mathrm{CP}$. Even though there were no data to justify the adjustment $(0.6 \mathrm{mV}$ to females' CV) of CP in this Japanese population, the gender-adjusted CP shifted the distribution of females' $\mathrm{CP}$ similar to that of males'. Therefore, this adjustment seemed reasonable to evaluate the CCS risk of the CP. On the other hand, the risk of the $\mathrm{CP}$ for predicting CCS morbidity in the total population depended largely on the CCS risk in females.

The CP was also found to be associated with CCS morbidity, even in subjects with a CP between 160.0 and $244.0 \mathrm{mV} \times \mathrm{ms}$. The CV and CP, which are used as markers of electrical remodeling, could also be early risk markers of CCS morbidity, because they represent myocardial electrical properties that include myocyte hypertrophy and cardiac fibrosis. It has been previously reported that the presence of $\mathrm{CP} \mathrm{LVH}$ ( $\geq 244.0 \mathrm{mV} \times \mathrm{ms}$ ) is predictive of future cardiovascular mortality regardless of the presence or absence of echocardiographic LVH. ${ }^{13,14}$ On the other hand, in the LIFE Study, ${ }^{20}$ in which those who fulfilled the $\mathrm{CP}$ or Sokolow-Lyon voltage criteria for ECG-LVH at baseline were enrolled, the CP, as a timevarying parameter, was found to be associated with cardiovascular mortality in patients with $\mathrm{CP} \geq 300.0 \mathrm{mV} \times \mathrm{ms}$, but not in those with a CP between 250.1 and $300.0 \mathrm{mV} \times \mathrm{ms}$ or those with a CP between 200.0 and $250.0 \mathrm{mV} \times \mathrm{ms}$. In a previous study, the CP was found to be associated with increased blood pressure and impaired glucose metabolism, ${ }^{17}$ and the results of the present study suggest that there should be further research into the effectiveness of early intervention against cardiovascular risk factors such as hypertension and/or impaired glucose metabolism in patients with a marginally increased CP.

The Sokolow-Lyon voltage was found to be associated with CCS morbidity, even in subjects with a voltage between 3.0 and $3.8 \mathrm{mV}$. In the Japanese Trial to Assess Optimal Systolic Blood Pressure in Elderly Hypertensive Patients (JATOS), ${ }^{24}$ patients with a Sokolow-Lyon voltage between 3.5 and $4.0 \mathrm{mV}$ were associated with an increased risk of cardiovascular events, and the ROC curve for predicting cardiovascular events was greater at the cutoff level of $2.7 \mathrm{mV}$. The results of our study in a general population support those of the JATOS study, ${ }^{24}$ which was performed in elderly hypertensive patients.

\section{Study Limitations}

The following limitations existed in the present study. (1) We did not obtain any data about echocardiographic LVH. Okin et $\mathrm{al}^{25}$ reported that the utility of ECG-LVH for detecting echocardiograhic LVH varies by race, although it was previously reported that the $\mathrm{CP}$ is associated with echocardiographic $\mathrm{LVH}$ in Japanese patients. ${ }^{22}$ (2) We did not obtain any data that would allow us to determine whether the $\mathrm{CV}$ adjustment used for females $(6 \mathrm{~mm})$ is appropriate for Japanese women. We performed parallel analyses using a CV adjustment of $4 \mathrm{~mm}$, and the results were broadly similar. (3) Measurement of ECG parameters was performed manually by a trained person, and the reproducibility of the measurements was confirmed.

\section{Conclusions}

Both the CV and CP were predictors of CCS morbidity in a general Japanese population. The predictive value of $\mathrm{CV}$ and $\mathrm{CP}$ in females was greater than in males. The $\mathrm{CV}$ and $\mathrm{CP}$ predicted CCS morbidity at lower quintile levels than are written in the current guideline of the JSH2009.

\section{Acknowledgments}

This study was supported by a Grant-in-Aid for Scientific Research from the Ministry of Education, Culture, Sports, Science, and Technology of Japan and grants from the Foundation for the Development of the Community, Tochigi, Japan.

\section{Disclosures}

None.

\section{References}

1. Jain A, Tandri H, Dalal D, Chahal H, Soliman EZ, Prineas RJ, et al. Diagnostic and prognostic utility of electrocardiography for left ventricular hypertrophy defined by magnetic resonance imaging in relationship to ethnicity: The Multi-Ethnic Study of Atherosclerosis (MESA). Am Heart J 2010; 159: 652-658.

2. Sokolow M, Lyon T. The ventricular complex in left ventricular hypertrophy as obtained by unipolar precordial and limb leads. Am Heart J 1949; 37: 161-186.

3. Molloy T, Okin P, Devereux R, Kligfield P. Electrocardiographic detection of left ventricular hypertrophy by the simple QRS voltageduration product. J Am Coll Cardiol 1992; 20: 1180-1186.

4. Ogihara T, Kikuchi K, Matsuoka H, Fujita T, Higaki J, Horiuchi M, et al. The Japanese Society of Hypertension Guidelines for the Management of Hypertension (JSH 2009). Hypertens Res 2009; 32: 3 107.

5. Hancock EW, Deal BJ, Mirvis DM, Okin P, Kligfield P, Gettes LS. AHA/ACCF/HRS recommendations for the standardization and interpretation of the electrocardiogram: Part V. Circulation 2009; 119: e251-e261, doi:10.1161/CIRCULATIONAHA.108.191097.

6. Casale PN, Devereux RB, Kligfield P, Eisenberg RR, Miller DH, Chaudhary BS, et al. Electrocardiographic detection of left ventricular hypertrophy: Development and prospective validation of improved criteria. J Am Coll Cardiol 1985; 6: 572-580.

7. Casale PN, Devereux RB, Alonso DR, Campo E, Kligfield P. Improved sex-specific criteria of left ventricular hypertrophy for clinical and computer interpretation of electrocardiograms: Validation with autopsy findings. Circulation 1987; 75: 565-572.

8. Kannel WB, Gordon T, Offutt D. Left ventricular hypertrophy by electrocardiogram. Prevalence, incidence, and mortality in the Framingham study. Ann Intern Med 1969; 71: 89-105.

9. Kannel W, Gordon T, Castelli W, Margolis J. Electrocardiographic left ventricular hypertrophy and risk of coronary heart disease: The Framingham Study. Ann Intern Med 1970; 72: 813-822.

10. Levy D, Salomon M, D'Agostino RB, Belanger AJ, Kannel WB. Prognostic implications of baseline electrocardiographic features and their serial changes in subjects with left ventricular hypertrophy. Circulation 1994; 90: 1786-1793.

11. Verdecchia P, Schillaci G, Borgioni C, Ciucci A, Gattobigio R, Zampi I, et al. Prognostic value of a new electrocardiographic method for diagnosis of left ventricular hypertrophy in essential hypertension. $J$ Am Coll Cardiol 1998; 31: 383-390.

12. Schillaci G, Battista F, Pucci G. A review of the role of electrocardiography in the diagnosis of left ventricular hypertrophy in hypertension. J Electrocardiol 2012; 45: 617-623.

13. Sundstrom J, Lind L, Arnlov J, Zethelius B, Andren B, Lithell HO. Echocardiographic and electrocardiographic diagnoses of left ventricular hypertrophy predict mortality independently of each other in a population of elderly men. Circulation 2001; 103: 2346-2351.

14. Kohsaka S, Sciacca RR, Sugioka K, Sacco RL, Homma S, Di Tullio MR. Additional impact of electrocardiographic over echocardiographic diagnosis of left ventricular hypertrophy for predicting the risk of ischemic stroke. Am Heart J 2005; 149: 181-186. 
15. Rodriguez-Padial L, Bacharova L. Electrical remodeling in left ventricular hypertrophy: Is there a unifying hypothesis for the variety of electrocardiographic criteria for the diagnosis of left ventricular hypertrophy? J Electrocardiology 2012; 45: 494-497.

16. Ishikawa S, Gotoh T, Nago N, Kayaba K. The Jichi Medical School (JMS) Cohort Study: Design, baseline data and standardized mortality ratios. J Epidemiol 2002; 12: 408-417.

17. Ishikawa J, Ishikawa S, Kabutoya T, Gotoh T, Kayaba K, Schwartz JE, et al; for the Jichi Medical School Cohort Study Investigators Group. Cornell product left ventricular hypertrophy in electrocardiogram and the risk of stroke in a general population. Hypertension 2009; 53: 28-34.

18. Ishikawa S, Kayaba K, Gotoh T, Nago N, Nakamura Y, Tsutsumi A, et al. Incidence of total stroke, stroke subtypes, and myocardial infarction in the Japanese population: The JMS Cohort Study. J Epidemiol 2008; 18: 144-150.

19. Okin PM, Roman MJ, Devereux RB, Kligfield P. Electrocardiographic identification of increased left ventricular mass by simple voltage-duration products. J Am Coll Cardiol 1995; 25: 417-423.

20. Okin PM, Devereux RB, Jern S, Kjeldsen SE, Julius S, Nieminen MS, et al; for the LIFE Study Investigators. Regression of electrocardiographic left ventricular hypertrophy during antihypertensive treatment and the prediction of major cardiovascular events. JAMA 2004; 292: $2343-2349$.

21. WHO MONICA Project Principal Investigators. The World Health Organization MONICA Project (monitoring trends and determinants in cardiovascular disease): A major international collaboration. $J$ Clin Epidemiol 1988; 41: 105-114.

22. Shirai T, Kasao M, Nozaki M, Nitta S. Evaluation of hypertensive cardiac abnormalities using the Cornell product. Circ J 2007; 71: 731-735.

23. Park JK, Shin JH, Kim SH, Lim YH, Kim KS, Kim SG, et al. A comparison of Cornell and Sokolow-Lyon electrocardiographic criteria for left ventricular hypertrophy in Korean patients. Korean
Circ J 2012; 42: 606-613.

24. Jissho S, Shimada K, Taguchi H, Yoshida K, Fukuda S, Tanaka H, et al. Impact of electrocardiographic left ventricular hypertrophy on the occurrence of cardiovascular events in elderly hypertensive patients: The Japanese trial to assess optimal systolic blood pressure in elderly hypertensive patients (JATOS). Circ J 2010; 74: 938-945.

25. Okin P, Wright J, Nieminen MS, Jern S, Taylor A, Phillips R, et al. Ethnic differences in electrocardiographic criteria for left ventricular hypertrophy: The LIFE study. Am J Hypertens 2002; 15: 663-671.

\section{Supplementary Files}

Supplementary File 1

Data S1. Methods

Figure S1. Distribution of Cornell voltage in (A) males and (B) females.

Table S1. Hazard ratios (HR) of each component of the Cornell voltage ( $\mathrm{R}$ in lead aVL and $\mathrm{S}$ in lead V3) and Sokolow-Lyon voltage (S in lead V1 and R in lead V5) for all-cause mortality and combined cardiovascular and stroke (CCS) morbidity and mortality in males

Table S2. Multivariate adjusted hazard ratios (HR) of the quintile of unadjusted Cornell product $(\mathrm{CP})$ for mortality and morbidity in Males and Females

Table S3. Multivariate adjusted hazard ratios (HR) of the quintile of Cornell product (CP) for mortality and morbidity in total subjects

Table S4. Multivariate adjusted hazard ratios (HR) of the quintile of Sokolow-Lyon voltage for mortality and morbidity in total subjects.

Please find supplementary file(s);

http://dx.doi.org/10.1253/circj.CJ-13-0470 